\title{
Lessons Learned from the Adaptations of Post-Flood Housing Reconstruction in Kuala Krai, Kelantan
}

\author{
Nik Nurul Hana Hanafi ${ }^{1}$, Juliza Mohamad ${ }^{2}$, \\ Siti Aisyah Muhammad ${ }^{1}$, Mhd. Hafiz Karami Mhd. Zain ${ }^{1}$ \\ ${ }^{1}$ Department of Architecture, Faculty of Architecture and Ekistics, Universiti Malaysia Kelantan, Malaysia, \\ ${ }^{2}$ Sheffield School of Architecture, University of Sheffield, UK,
}

hana.h@umk.edu.my, mjuliza1@sheffield.ac.uk, aisyah@umk.edu.my, hafiz.k@umk.edu.my

Tel of 1 st Author: $+6012-9454640$

\begin{abstract}
The outcome of post-disaster housing (PDH) in Malaysia, particularly in Kuala Krai Kelantan, has remained unexplored. Therefore, this paper attempted to discover the project impacts in Kampung Manek Urai Lama by investigating housing adaptation and modification. Accordingly, this study employed a case study method involving 18 respondents through purposive sampling. Findings revealed that the original house design does not consider several spatial needs and living traditions; the result established that these shortcomings were the main factors affecting the housing modifications. Thus, the outcome of this study presents discoveries that can facilitate disaster management in Malaysia, specifically when planning for future post-disaster housing.
\end{abstract}

Keywords: housing reconstruction, post-disaster adaptation, post-disaster housing, housing modification

eISSN: 2398-4287@ 2021. The Authors. Published for AMER ABRA CE-Bs by e-International Publishing House, Ltd., UK. This is an open access article under the CC BYNC-ND license (http://creativecommons.org/licenses/by-nc-nd/4.0/). Peer-review under responsibility of AMER (Association of Malaysian Environment-Behaviour Researchers), ABRA (Association of Behavioural Researchers on Asians/Africans/Arabians) and CE-Bs (Centre for Environment-Behaviour Studies), Faculty of Architecture, Planning \& Surveying, Universiti Teknologi MARA, Malaysia.

DOI: https://doi.org/10.21834/ebpj.v6i17.2820

\subsection{Introduction}

Unprecedented flooding had struck Malaysia in December 2014, due to extreme rainfall and unusual wind intensity during the Northeast Monsoon season. The state of Kelantan, located in the East coast of Peninsular Malaysia, was identified as one of the most affected states, with 9 out of 10 districts being inundated by the flood. The Kelantan river basin recorded 229.64 mm of rainfall, which was the highest amount of rain in 45 years (Othman, Zakaria, Ab. Ghani, Chang, \& Chan, 2016). Kuala Krai in Kelantan was the hardest-hit district with the most numbers of villagers had to be evacuated as the water level had increased up to 10 meters and had inundated buildings up to the 4th floor (Anua \& Chan, 2020). In certain parts of Kuala Krai, people had to seek refuge on the nearest hill when the evacuation centres were eventually submerged, where at that juncture Kelantan was nearly paralysed.

Villagers began to return home when the flood receded after one week, only to discover that there was no home to return to. Thousands of houses, mostly timber houses, had been severely damaged or washed away by the flood. Infrastructures, including concrete bridges and railway tracks, were also destroyed. Some news had reported that the destruction appeared to be as intense as a tsunami aftermath. The flood was perceived to have caused the worst devastation in Kelantan within the past 100 years (Wan Ahmad \& Abdurahman, 2015).

eISSN: 2398-4287@ 2021. The Authors. Published for AMER ABRA cE-Bs by e-International Publishing House, Ltd., UK. This is an open access article under the CC BYNC-ND license (http://creativecommons.org/licenses/by-nc-nd/4.0/). Peer-review under responsibility of AMER (Association of Malaysian Environment-Behaviour Researchers), ABRA (Association of Behavioural Researchers on Asians/Africans/Arabians) and cE-Bs (Centre for Environment-Behaviour Studies), Faculty of Architecture, Planning \& Surveying, Universiti Teknologi MARA, Malaysia.

DOI: https://doi.org/10.21834/ebpj.v6i17.2820 
Apart from immediate relief assistance, the Government and other organisations had consecutively constructed temporary shelters and transit houses to accommodate the homeless. Housing reconstruction was established as the urgent assistance in the aftermath of the flood. According to the National Disaster Management Agency (NADMA), 1295 houses replacement were needed to be rebuilt in various villages across Kuala Krai. In providing the house replacement for victims of the disaster, numerous local and international housing donors had developed their respective design proposal, based on their beliefs as to what the victims needed to have. As a result, diverse housing designs with different spaces and sizes were built across the district within two years. It was made explicit to the nation that disaster victims had finally received a place that they can call home. However, what remains unspoken is the impact of the completed housing reconstruction and the occupants' adaptation during occupancy.

\subsection{The Outcome of Post-disaster Housing Reconstruction}

Housing reconstruction possesses an excellent opportunity to assist in rebuilding the lives of the affected community when it is carried out in response to the local culture and climate, is durable and easily maintained, is made adaptable for future living, and is developed with the beneficiaries' participation (da Silva, 2010). The failure to equalise between housing needs and housing reconstruction may cause dissatisfaction among the occupants. This dissatisfaction may lead them to modify the house or worst, to reject the house and move to another place (Ghaffarianhoseini, Berardi, Dahlan, \& Ghaffarianhoseini, 2014). Significantly, poor housing conditions and housing environment are linked to psychological distress among the occupants (Shafi, Arif, Haroon, \& Balagamwala, 2019); numerous studies on occupancy experience have revealed that occupants are facing difficulties in their daily lives due to various housing problems (examples are: Dikmen \& Elias-Ozkan, 2016; Kürüm Varolgüneş, 2020; Rahmayati, 2016a; Sanderson, Sharma, \& Anderson, 2012).

Evaluating PDH reconstruction is integral to ascertain whether the housing project has contributed to the post-disaster recovery or further assistance is needed (Ali, Mannakkara, \& Wilkinson, 2020; da Silva, 2010; Wijegunarathna, Wedawatta, Prasanna, \& Ingirige, 2018). Assessing experience of the occupants could imply the housing acceptance and the impact of the project towards the communities (He, Aitchison, Hussey, \& Chen, 2019; Kotani, Honda, Imoto, Shakya, \& Shrestha, 2020). Moreover, evaluating occupancy and identifying occupants' experience could be used as criterion to improve future projects (Murao, 2020).

In the case of Kuala Krai, the impact of the PDH on the occupants remains undiscovered. Minimal attention was given to understand how the house replacement had influenced the occupants and how they adapted to the new house setting. With the above justification, this paper argues that it is necessary to assess the adaptations within the completed house, and this should be conducted in order to recognise whether it has supported the post-disaster recovery or has imposed further challenges. Therefore, the objectives of this study are to examine how the residents have adapted to the new house setting after the 2014-flood in Kuala Krai and to explore the common house adaptations that have been carried out within the housing scheme. Accordingly, a case study was conducted in a village in Kuala Krai, Kelantan to uncover the housing adjustment and motivational needs behind every adjustment.

\subsection{Housing Adaptation and Modification}

Architecturally, a house has numerous affordances such as affording shelter, comfort, and etcetera. Affordances are often relative to the people's specific needs as they relate to what are offered, what are provided or furnished for the receivers (Gibson, 2015). In most cases, housing adaptation and modification provide improvements in the people's living experience; as such it portrays who the people are and what they genuinely need. In the literature, the terms housing adaptation and modification are often used interchangeably to describe adjustments that have been made to a house. Housing modification involves a broader range of interventions, where the deficiencies of the existing house are being provided for as per occupants' needs (Rahim \& Hashim, 2012). Adaptation, on the other hand, is essential until at least housing modification can be made possible. Housing adaptation denotes that the occupants need to improve their living conditions to afford normal functioning in response to the constraints in their house.

\subsection{People's Adaptations in Post-Disaster Setting}

In the context of a post-disaster, adaptation could indicate the occupants' attempt to be in control of the socio-spatial organisations of their houses and to transform the new surrounding into places of culture and meanings (Barenstein, 2015). On the contrary, physical adjustments which have resulted from the dissatisfaction with the housing design could be considered as an indication of an unsuccessful post-disaster project (Dikmen \& Elias-Ozkan, 2016).

Barenstein (2015) conducted a longitudinal study in a post-earthquake resettlement village in Gujarat, India, to determine the people's coping strategies over the socio-spatial organisation of the village. The first study in 2004 revealed that $90 \%$ of villagers were highly dissatisfied with the new house. Eight years later, the same community had established adaptations where houses had been transformed to afford privacy needs, spatial needs, and thermal comfort. The community undertook the changes following their traditional lifestyle and cultural needs, which were not considered in the original donated house. It was discovered that their traditional and cultural beliefs were significantly valued, thus, housing adaptations were made to preserve their traditions regardless of the housing condition.

In Hambantota, Sri Lanka, the occupants were found to have made improvement on their living conditions since the rectification of the post-tsunami resettlement planning mistakes was far more complex. The villagers had made adaptations to continue living in that new settlement by managing sanitation and in ensuring their safety (Ahmed \& McEvoy, 2014). It was apparent that the community possessed adaptive skills and was not merely passive receivers.

Additionally, housing adaptations or modifications are also considered as the occupants' responses to deficiencies of the housing attributes. It could signify that the occupants' socio-cultural values have been adversely affected (Rahmayati, 2016b). Literatures had revealed that dissatisfaction among the occupants could be seen from the adjustments that were made to the existing house. 
In a study that examined housing reconstruction in Aceh after the 2004 tsunami, Rahmayati (2016a) discovered that the space constraints of the house had caused difficulties to the occupants and they had to alter their traditional practices, which were distressing particularly in a cultural-rich place such as Aceh. In preserving their traditions, Acehnese were forced to modify their house to meet their needs. This modification involved additional costs, which could have been avoided if the housing donors have provided what has been promised.

Another study that was conducted on a post-disaster settlement in Cagayan de Oro, in the Philippines also highlighted numerous modifications made by the villagers, despite the illegality, in order to ease their daily activities. Adjustments were made to fulfil their spatial needs, economic needs and to achieve certain functional spaces which were not considered in the initial house design (Carrasco, Ochiai, \& Okazaki, 2017).

The above studies had demonstrated that PDH could positively or negatively affect the occupants. While PDH should be better rebuilt, certain deficiencies in housing had led to modifications which imposed additional psychological and financial burden on the occupants.

\subsection{Methodology}

This research employed case study as the basis for research methodology. The study commenced by selecting the case study area, Kampung Manek Urai Lama, which is located $25 \mathrm{~km}$ from the Kuala Krai town center. It represents a typical Malay village in rural Kelantan in a pre-disaster setting, with most houses made of timber. At the point of this study, the total number of reconstructed houses in the village was 68 units; 48 units were built by the Federal Government through the Public Works Department (JKR), 14 units by various NGOs, four units by the State Government and two units by the Majlis Agama Islam dan Adat Istiadat Melayu Kelantan.

Houses built by JKR which are of the majority in numbers have been chosen in this study. The numbers of RKB houses could enhance the selection of modification variations compared to other housing schemes. The housing scheme, which was called Rumah Kekal Baru (RKB) or New Permanent House, was built on the beneficiaries' own land.

Semi-structured interview was conducted in order to address the first research objective. The required data for this objective were their experience living in the original house and what were their ways of coping towards the housing adequacy or deficiency. This interview also allowed the probing of viewpoints and stories related to the objective. To fulfil the second objective, observation was carried out to explore the common motivations behind every house adaptation.

This study adopted purposive sampling to purposely select houses with adaptations. Unfortunately, the researchers could not obtain the exact numbers of the modified houses from the authorities (Majlis Daerah Kuala Krai) because the data did not exist. The exact plot locations were also unidentified. Hence this research also employed snowball sampling technique in order to obtain referrals from villagers who had modified their houses. A total of 18 respondents agreed to be interviewed. The interview was ceased when the relevant data had reached saturation.

\subsection{Findings and Discussion}

RKB could be identified by the distinct beige and blue colours of the exterior walls and the Malaysian Coat of Arms at the entrance door. These houses were built in reinforced concrete frame and brick walls which contributed to the new appearance of the overall village setting. The beneficiaries had the option to choose between two types of house design: Type 1 (RKB1) and Type 2 (RKB2). The descriptions of the two options are summarised in Table 1.

Figures 1(a) and (b) above present the house design of both house types with distinct features: RKB1 is built $2.4 \mathrm{~m}$ above the ground while RKB2 is built on the ground level. However, the reasons behind the differences in the house features were unknown. It was unclear if the provision of stilts was intended to withstand future floods or to exemplify the traditional Malay house design that was built on stilts. Figure 2 below depicts the organisation of the space in RKB1. It features one staircase, terrace, living and dining area, three bedrooms, one kitchen, one toilet, and one bathroom. There was only one access door provided.

Table 1. Summary of RKB1 and RKB2

\begin{tabular}{lll} 
& \multicolumn{2}{c}{ Table 1. Summary of RKB1 and RKB2 } \\
\hline Description & RKB1 & RKB2 \\
\hline Type & On stilts $(2.4 \mathrm{~m}$ above the ground $)$ & On the ground \\
Floor area & $667 \mathrm{ft}^{2}\left(62 \mathrm{~m}^{2}\right)$ & $818 \mathrm{ft}^{2}\left(76 \mathrm{~m}^{2}\right)$ \\
Spaces & Living and dining & Living and dining \\
& Three bedrooms & Three bedrooms \\
& 1 Kitchen & 1 Kitchen \\
& 1 Toilet & 2 Bathrooms \\
& 1 Bathroom & \\
\hline
\end{tabular}




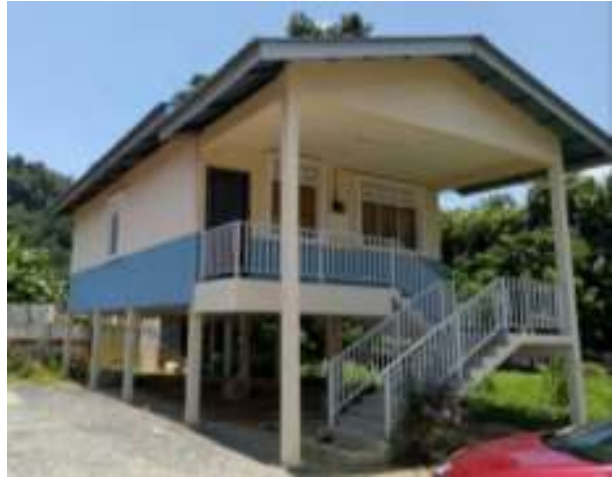

(a)

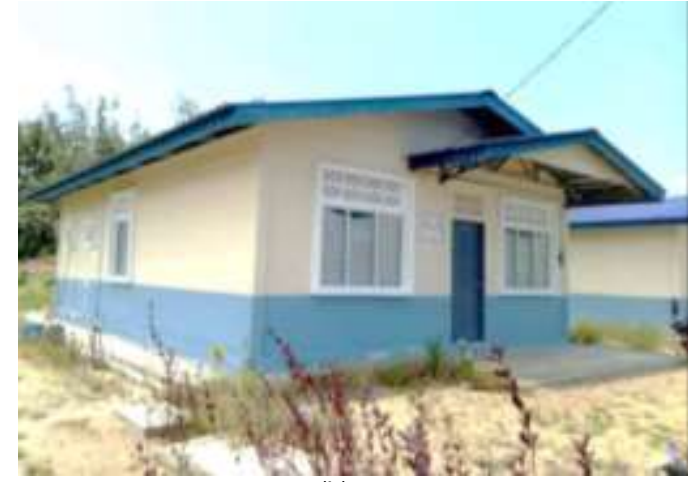

(b)

Fig. 1. (a) RKB Type 1 (RKB1); (b) RKB Type 2 (RKB2.

(Source: Authors)

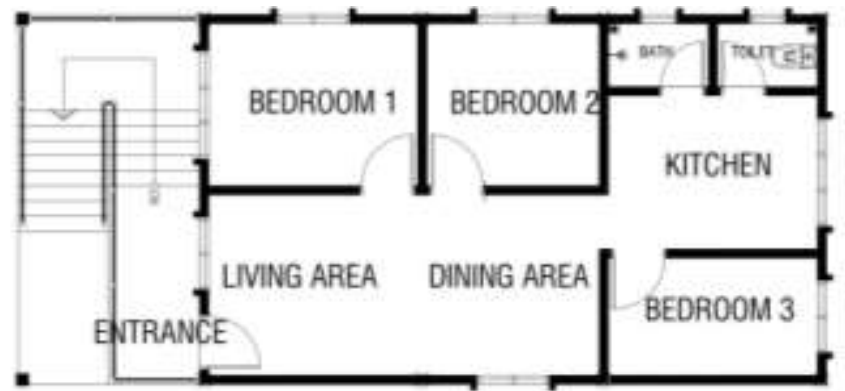

Fig. 2. Floor plan of RKB1

Figure 3 portrays the floor plan of RKB2 featuring the spaces, namely the living and dining area, three bedrooms, one kitchen, and two bathrooms. This house design has two access doors.

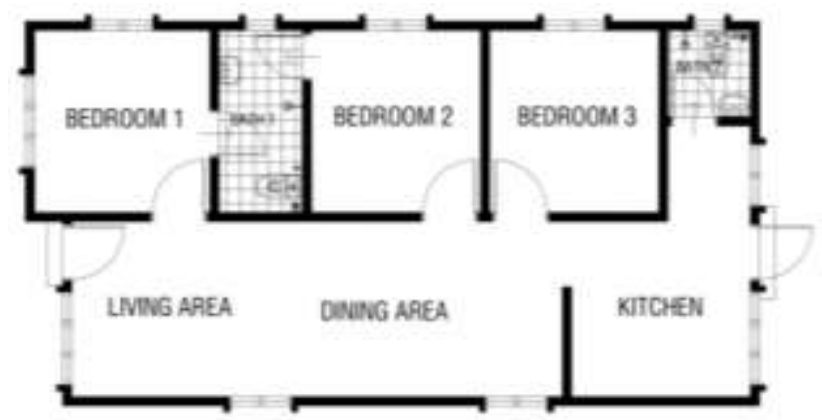

Fig. 3. Floor plan of RKB2

\subsection{Housing Choice and Physical Adjustments}

Firstly, the respondents were asked about the reasons behind their housing choice. $90 \%$ of RKB1 occupants expressed that they purposely chose RKB1 because they recognised that the design could be modified later by enclosing the space underneath the house to get more rooms for the family. In contrast, occupants of RKB2 responded that they selected the option because it has more extensive floor area which felt sufficient for living condition. This indicated that the floor area was the primary concern for the house selection. Those who needed more spaces had considered adding more rooms even before the actual housing construction.

Through observation, numerous physical adjustments were made to the original house designs, which suggested that occupants had been actively adapting their houses. Most of the modifications could be identified externally. It was also discovered that the physical adjustment or modifications were made without consulting experts (architect or engineer); hence it was unknown if the existing structural ability might be affected by the new modifications. This scenario was common in rural Kelantan, where houses were built or modified without building approval from the local authority (Roosli \& Collins, 2016). Additionally, the findings from this study suggested that physical adaptations were carried out progressively, primarily due to their financial constraints. In rural areas such as in Kuala Krai, people are already facing challenges in their financial resources (Apurva, Sharareh, \& Elnaz, 2020; Kotani et al., 2020), hence adjustments that were made to the house are genuinely due to their basic needs rather than for self-identity or image. This study discovered at least three major motivations behind every house adaptation Kampung Manek Urai Lama. These concerns have been categorised into spatial needs, functional affordances, and economic affordances, and are discussed below: 


\subsubsection{Spatial needs}

The spatial need was found to be the most frequent reason for house modifications in RKB1. The investments were predominantly influenced by the size of the household, where it is common in Kelantan to have extended family living together under one roof. It was learned that the space underneath the house, although only $2.4 \mathrm{~m}$ height, was perceived as an opportunity to fulfil their needs. $90 \%$ of RKB1 occupants had enclosed the space with a brick wall and had constructed several rooms on the ground. The one-story house that was built on stilts had become a 2-story house. Figures 4 (a) and (b) below illustrate examples of the adjustments that have been made to the spaces on the ground. $10 \%$ of RKB1 occupants have planned to undertake similar adjustments when they can afford to.

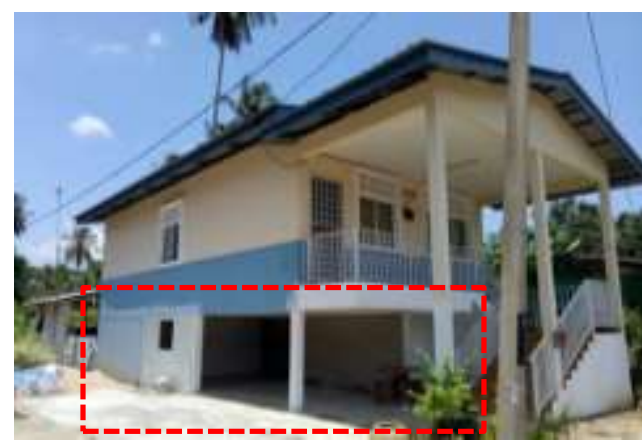

(a)

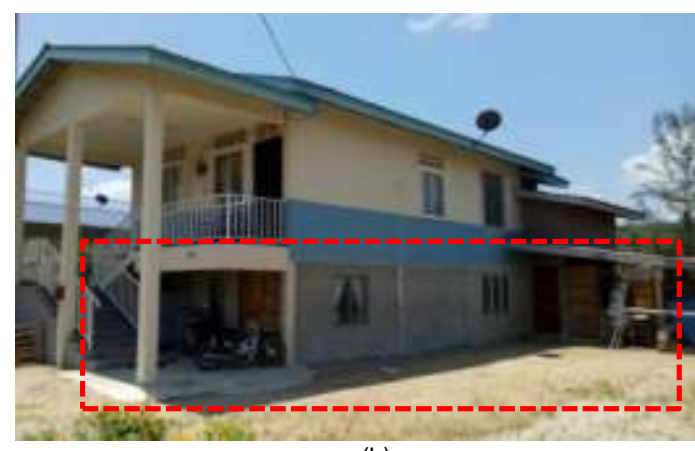

(b)

Fig. 4. (a)\& (b) Example 1 of RKB1 modification; (b) Example 2 of RKB1 modification. (Source: Authors)

\subsubsection{Functional affordances}

Functional affordances in this study mainly denote the adaptation carried out by the occupants in order for a space to be suited to serve its purpose well. By improving certain housing attributes, they were able to minimise interruptions in their living norms which were caused by the weaknesses of the initial house design. The most frequent adaptations were evident in RKB2, where a porch was constructed at the front part of the house. Functionally, it was accomplished as a weather protection for vehicles and for clothes drying. Several households had created sitting areas at the porch to receive guests, especially the unfamiliar ones, as per shown in Figures 5 (a) and (b) below. Inherently, the porch could represent an anjung, a covered exterior space that was generally found in traditional Malay houses as segregation between the semi-private area (anjung) and private areas (the main house). Interestingly, the interviews for this study were also undertaken at the porch. This provision indicated that intrinsic values of Malay culture still persisted regardless of the housing condition.

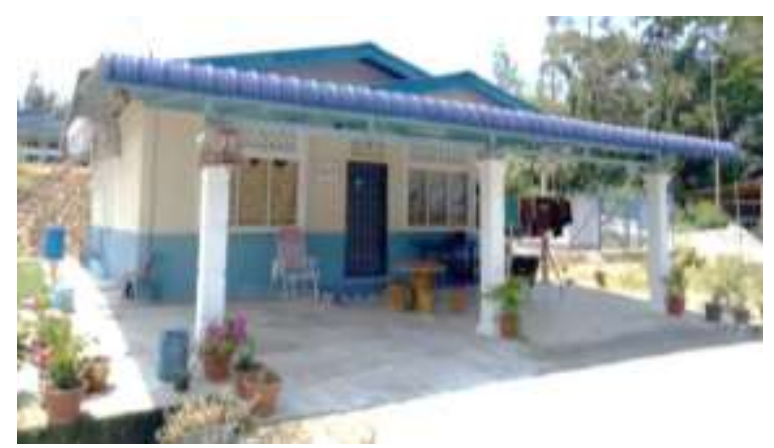

(a)

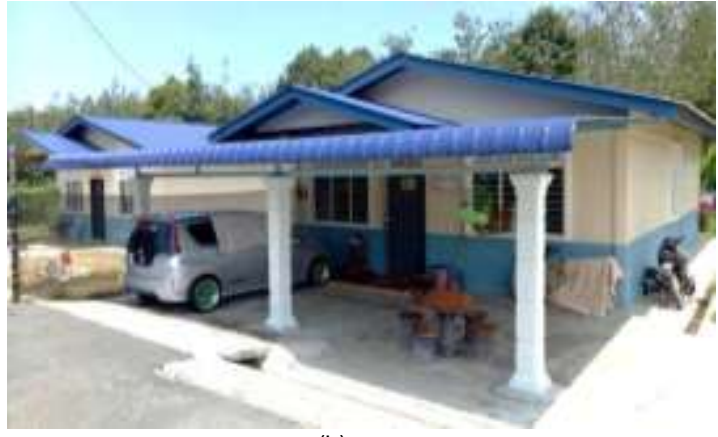

(b)

Fig. 5. (a)Example 1 of RKB1 modification; (b) Example 2 of RKB1 modification. (Source: Authors)

Apart from that, the occupants in RKB1 had also made adjustments to minimise difficulties in their routines. RKB1 is characterised by one staircase that leads to one access door. The absence of secondary door in the initial house design had caused inconveniences therefore they had constructed additional spaces on the ground level with additional access door, as shown in Figure 4(b) in previous section. In this regard, an internal staircase was also added to improve internal circulation. Figure 5 below illustrates an example of adjustments made to a RKB1 in order to afford conveniences in their daily activities, where an internal staircase was constructed to connect the 1 st floor level of the existing house and the newly constructed spaces on the ground level.

Additionally, $80 \%$ of the occupants in RKB1 mentioned that they had constructed an additional toilet and bathroom at the back of the house. They perceived the separation of toilet and bathroom as practical since, as Muslims, they can perform ablution in the bathroom and away from the water closets. Besides, most villagers were still washing clothes by hand, and this was done in the bathroom. 


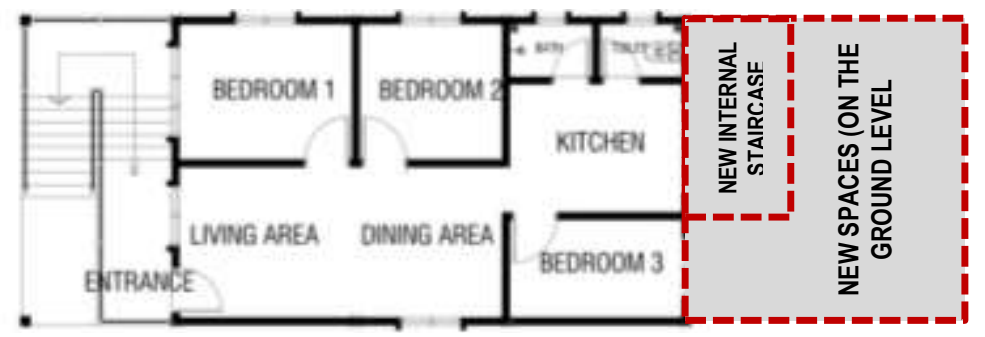

Fig. 5. Example of new additional spaces constructed in RKB1

\subsubsection{Economic affordances}

Economic affordances refer to the adaptations by which the occupants had conducted in order to fulfil economic benefits. This study revealed that $50 \%$ of the occupants had constructed stalls that were attached to their house so as to accommodate home-based business, and had extended the kitchen for food production business. The purpose of the adaptations is to continue their pre-flood business; it is a common scenario in Kelantan to conduct business at home. Figures 7(a) and 7(b) below portray an example of this adaptation where the occupants have constructed structures that are attached to the existing house. This suggested that the occupants had attempted to resume their pre-flood activities and to re-establish a familiar environment by conducting income-generating activities at home. This finding corresponded with He et al. (2019) which underlined the importance of a familiar living mode in supporting postdisaster recovery. The adaptation in regards to their livelihood could also imply their coping strategies as per discovered in a study by Sina, Chang-Richards, Wilkinson, \& Potangaroa (2019).

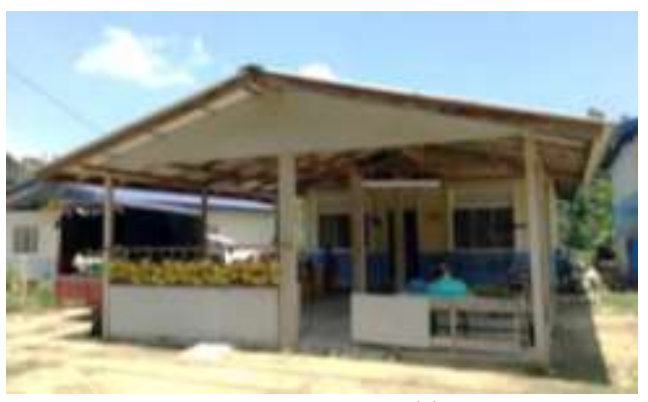

(a)

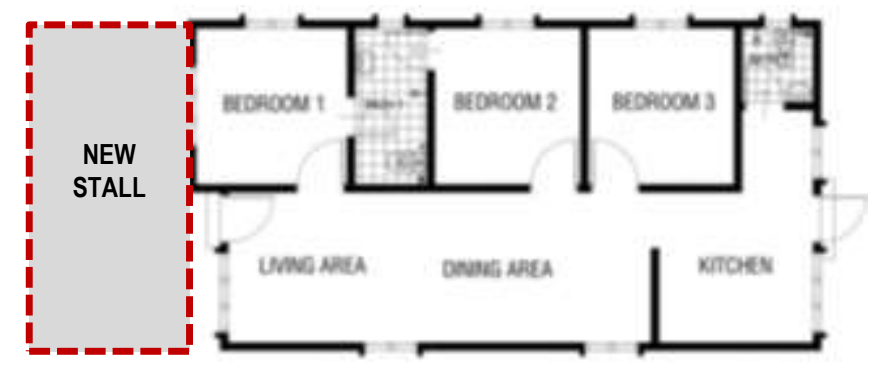

(b)

Fig. 7(a) Example of attached structures in RKB2; (b) Illustration of new stall in RKB2

The above motivations had justified how occupants in the post-flood housing reconstruction in Kampung Manek Urai Lama had responded to their respective donated house and had transformed it into a space that supported their overall needs in order to maintain normal functioning. The analysis suggested that the space adjustments were direct translation of their daily activities, cultural and traditional values.

\subsection{Conclusion and Recommendations}

The foregoing findings demonstrated that the community had attempted to recreate pre-disaster environment in the current post-disaster setting. Their values and traditions persisted regardless of the house condition. It was apparent that the housing reconstruction in Kampung Manek Urai Lama had missed the opportunity to support immediate post-disaster recovery as the house design did not consider specific housing attributes, local traditions and living norms. These shortcomings had imposed further challenges and difficulties to the occupants, and were discovered to be the major reasons for housing adaptations and modification.

The analysis has highlighted that there is a need to improve the current PDH scheme in Malaysia. A complete and precise context to understand the victims of a disaster is integral in providing planning for post-disaster housing. This study also emphasised the significance of evaluating PDH projects, ignoring which, similar problems may reoccur in the next project. After all, a house in a disaster setting is not only about providing shelter, but it should be able to accommodate longer-term disaster recovery for the community at large.

This research has been carried out based on a one-time data collection. Studies that have been conducted later than this current research might generate different results, in the view that human behaviour, financial resources and other factors may evolve over time. As a suggestion for future research, assessment may be conducted within multiple periods of occupancy since longitudinal study might reveal other adaptations that have not occurred during the current study. Research including intervention in the housing design such as a flexible design or an adaptable design, could be helpful in the future planning for PDH. 


\section{Acknowledgements}

The authors wished to convey their appreciation to Universiti Malaysia Kelantan for funding this research.

\section{Paper Contribution to Related Field of Study}

The findings of this research established that building donors should not disregard the actual needs and traditions of disaster victims. It is essential to learn from this outcome to develop better strategies in PDH project. When the actual shortcomings of the housing had been identified, it would be viable to create appropriate solutions. The specific contribution of this study could facilitate the related parties in post-disaster planning and recovery including the Government as the building actors and donors, academics as the potentials in research development, and consultants in managing the project on-site.

\section{References}

Ahmed, I., \& McEvoy, D. (2014). Post-tsunami resettlement in Sri Lanka and India: site planning, infrastructure and services. International Journal of Disaster Resilience in the Built Environment, 5(1), 53-65. https://doi.org/10.1108/IJDRBE-08-2012-0028

Ali, R. A., Mannakkara, S., \& Wilkinson, S. (2020). Factors affecting successful transition between post-disaster recovery phases: a case study of 2010 floods in Sindh, Pakistan. International Journal of Disaster Resilience in the Built Environment, 11(5), 597-614. https://doi.org/10.1108/IJDRBE-03-2020-0016

Anua, N., \& Chan, N. W. (2020). Community Resilience Building In The Aftermath Of Flood Disaster. European Proceedings of Social and Behaviour Sciences, (86), 501510. https://doi.org/10.15405/epsbs.2020.10.02.45

Apurva, P., Sharareh, K., \& Elnaz, S. (2020). Challenges in Post-Disaster Housing Reconstruction: Analysis of Urban vs. Rural Communities. Proceedings of the Creative Construction E-Conference, 103-110. https://doi.org/10.3311/ccc2020-061

Barenstein, J. D. (2015). Continuity and change in housing settlement patterns in post-earthquake Gujarat, India. International Journal of Disaster Resilience in the Built Environment, 6(2), 140-155. https://doi.org/10.1108//JDRBE-01-2014-0009

Carrasco, S., Ochiai, C., \& Okazaki, K. (2017). Residential satisfaction and housing modifications A study in disaster-induced resettlement sites in Cagayan de Oro Philippines. International Journal of Disaster Resilience in the Built Environment, 8(2). https://doi.org/10.1108//JDRBE-06-2012-0019

da Silva, J. (2010). Lessons from Aceh: Key Considerations in Post-Disaster Reconstruction. Practical Action Publishing. https://doi.org/10.4324/9781849775137

Dikmen, N., \& Elias-Ozkan, S. T. (2016). Housing after disaster: A post occupancy evaluation of a reconstruction project. International Journal of Disaster Risk Reduction 19(October), 167-178. https://doi.org/10.1016/j.jjdrr.2016.08.020

Ghaffarianhoseini, A., Berardi, U., Dahlan, N. D., \& Ghaffarianhoseini, A. (2014). What can we learn from Malay vernacular houses? Sustainable Cities and Society, 13, 157-170. https://doi.org/10.1016/j.scs.2014.04.008

Gibson, J. J. (2015). The theory of affordances. In The Ecological Approach to Visual Perception (Classic Ed, pp. 119-136). Psychology Press, Taylor \& Francis. https://doi.org/10.1075//sse.2.03bli

Hayles, C. S. (2010). An examination of decision making in post disaster housing reconstruction. International Journal of Disaster Resilience in the Built Environment 1(1), 103-122. https://doi.org/10.1108/17595901011026508

He, L., Aitchison, J. C., Hussey, K., \& Chen, Y. (2019). Building new houses or long-term recovery? A combination of quantitative and qualitative evidence from earthquakedisplaced households in Sichuan, China. Habitat International, 83(July 2018), 135-145. https://doi.org/10.1016/j.habitatint.2018.12.002

Kotani, H., Honda, R., Imoto, S., Shakya, L., \& Shrestha, B. K. (2020). Transition of post-disaster housing of rural households: A case study of the 2015 Gorkha earthquake in Nepal. International Journal of Disaster Risk Reduction, 44(March 2019), 101443. https://doi.org/10.1016/j.ijdrr.2019.101443

Kürüm Varolgüneş, F. (2020). Post-disaster permanent housing: the case of the 2003 Bingöl earthquake in Turkey. Disaster Prevention and Management: An International Journal, 30(2), 77-93. https://doi.org/10.1108/DPM-09-2019-0307

Murao, O. (2020). Recovery curves for housing reconstruction from the 2011 Great East Japan Earthquake and comparison with other post-disaster recovery processes. International Journal of Disaster Risk Reduction, 45, 101467. https://doi.org/10.1016/j.ijdrr.2019.101467

Othman, M. A., Zakaria, N. A., Ab. Ghani, A., Chang, C. K., \& Chan, N. W. (2016). ANALYSIS OF TRENDS OF EXTREME RAINFALL EVENTS USING MANN KENDALL TEST : A CASE STUDY IN PAHANG AND KELANTAN RIVER BASIN Jurnal Teknologi ANALYSIS OF TRENDS OF EXTREME RAINFALL EVENTS USING MANN KENDALL TEST : A CASE STUDY IN PAHANG AND KELANTAN RIVER. Jurnal Teknologi (Sciences \& Engineering), 4, 63-69. https://doi.org/10.11113/jt.v78.9696

Preiser, W. F. E. (1995). Post-occupancy evaluation: how to make buildings work better. Facilities, 13(11), 19-28. https://doi.org/10.1108/02632779510097787

Rahim, Z. A., \& Hashim, A. H. (2012). Adapting to Terrace Housing Living in Malaysia. Procedia - Social and Behavioral Sciences, 36(June 2011), 147-157. https://doi.org/10.1016/j.sbspro.2012.03.017

Rahmayati, Y. (2016a). Post-disaster housing: Translating socio-cultural findings into usable design technical inputs. International Journal of Disaster Risk Reduction, 17, 173-184. https://doi.org/10.1016/j.jjdr.2016.04.015

Rahmayati, Y. (2016b). Reframing "building back better" for post-disaster housing design: a community perspective. International Journal of Disaster Resilience in the 
Built Environment, 7(4), 344-360. https://doi.org/10.1108//JDRBE-05-2015-0029

Roosli, R., \& Collins, A. E. (2016). Key Lessons and Guidelines for Post-Disaster Permanent Housing Provision in Kelantan, Malaysia. In Procedia Engineering (Vol. 145, pp. 1209-1217). Elsevier B.V. https://doi.org/10.1016/j.proeng.2016.04.156

Sanderson, D., Sharma, A., \& Anderson, J. (2012). NGO permanent housing 10 years after the Gujarat earthquake: revisiting the FICCI-CARE Gujarat rehabilitation programme. Environment and Urbanization, 24(1), 233-247. https://doi.org/10.1177/0956247811431218

Shafi, K., Arif, F., Haroon, S., \& Balagamwala, M. (2019). Impact of housing conditions on psycho-social health of residents. Journal of Psychiatry and Behavioral Sciences, 2(1).

Sina, D., Chang-Richards, A. Y., Wilkinson, S., \& Potangaroa, R. (2019). A conceptual framework for measuring livelihood resilience: Relocation experience from Aceh, Indonesia. World Development, 117, 253-265. https://doi.org/10.1016/j.worlddev.2019.01.003

Wan Ahmad, W. I., \& Abdurahman, S. M. (2015). Kelantan Flood 2014: Reflections from Relief Aid Mission to Kampung Kemubu, Kelantan. Mediterranean Journal of Social Sciences, 6(3), 340-344. https://doi.org/10.5901/mjss.2015.v6n3s2p340

Wijegunarathna, E. E., Wedawatta, G., Prasanna, L. J., \& Ingirige, B. (2018). Long-term satisfaction of resettled communities: An assessment of physical performance of post-disaster housing. In Procedia Engineering (Vol. 212, pp. 1147-1154). Elsevier B.V. https://doi.org/10.1016/j.proeng.2018.01.148 